\title{
Hormone Related Risk Factors and Breast Cancer: Hospital Based Case Control Study from India
}

\author{
Unmesh Takalkar ${ }^{1}$, Shilpa Asegaonkar ${ }^{2}$, Pushpa Kodlikeri ${ }^{3}$, Ujwala Kulkarni ${ }^{4}$, \\ Virendrakumar Borundiya ${ }^{4}$ and Suresh Advani ${ }^{5}$ \\ ${ }^{1}$ UNITED CIIGMA Hospital Aurangabad, Maharashtra, India \\ ${ }^{2}$ Biochemistry, Course in Clinical Nutrition, Department of Biochemistry, Government Medical \\ College Aurangabad, Maharashtra India \\ ${ }^{3}$ Kodlikeri Memorial Hospital \& CIIGMA Hospital Aurangabad, India \\ ${ }^{4}$ Research Department, Kodlikeri Memorial Hospital \& CIIGMA Hospital Aurangabad, India \\ ${ }^{5}$ Kodlikeri Memorial Hospital \& Cllgma Hospital, Asian Institute of Oncology, S. L. Raheja Hospital, \\ Raheja Hospital Road, Mahim, Mumbai
}

Correspondence should be addressed to: Unmesh Takalkar; drunmesh.aurangabad@gmail.com

Received Date: 2 January 2014; Accepted Date: 13 March 2014; Published Date: 26 April 2014

Academic Editor: Manuel Neves-E-Castro

Copyright @ 2014 Unmesh Takalkar, Shilpa Asegaonkar, Pushpa Kodlikeri, Ujwala Kulkarni, Virendrakumar Borundiya and Suresh Advani. Distributed under Creative Commons CC-BY 3.0

\begin{abstract}
Breast cancer is the second most common malignancy in Indian women. Basically it is a hormone mediated disorder due to continuous exposure to ovarian hormones. Several established modifiable and non modifiable risk factors influence hormonal status which is associated with breast cancer. Prevalence and profile of risk factors of breast cancer differs region wise. Although etiology of breast cancer is complex and multifactorial involving genetic, hormonaland environmental factors, various studies showed significant role of reproductive risk factors in breast tumor genesis. Present study was aimed to explore association of various hormone related risk factors with breast cancer in Indian women.
\end{abstract}

This hospital based case control study included newly diagnosed cases of breast cancer and age matched healthy women as controls. Standard structured pretested valid questionnaire was administered to record socio demographic data, medical, family, past history, use of hormones and reproductive risk factors. Participants were asked about marital status, number of live births, abortions, age at first live birth and breastfeeding duration history. Information was also obtained regarding age at menarche, menopausal status, age at menopause and use of oral contraceptives and hormone replacement therapy. Anthropometric measures body mass index and waist: hip ratio were taken as index of adiposity.

Cite this Article as: Unmesh Takalkar, Shilpa Asegaonkar, Pushpa Kodlikeri, Ujwala Kulkarni, Virendrakumar Borundiya and Suresh Advani (2014), "Hormone Related Risk Factors and Breast Cancer: Hospital Based Case Control Study from India," Research in Endocrinology, Vol. 2014 (2014), Article ID 872124, DOI: $10.5171 / 2014.872124$ 
We found significant association $(\mathrm{p}<0.05)$ of age, menopausal status, use of oral contraceptives and postmenopausal obesity with breast cancer in comparison with controls.

Present study has provided possible association of hormone related risk factors in breast cancer in Indian population.

Keywords: Breast cancer, hormone, reproductive risk factors.

\section{Introduction}

Breast cancer is the second most frequent cancer and cancer related death among women. In spite of widely available screening measures and advanced therapeutic modalities, it remained a serious public health concern in both, developed and developing countries. With rapid economic and social transition, prevalence of breast cancer is increasing at rapid pace worldwide. In India, its incidence varies from 12 - 31 cases per 100000 women with newly diagnosed 75000 cases per year (1). Recently Indian Council of Medical Research predicted the number of breast cancer cases in India to rise to 106,124 in 2015 and to 123,634 in 2020 (2).

Breast cancer is a heterogeneous multifactorial disease caused due to genetic, reproductive, environmental, and dietary and lifestyle related risk factors. Basically it is a hormone mediated disorder due to continuous exposure to ovarian hormones. Sex hormones are associated with breast cancer among which Estrogen plays central role in the development of mammary glands. (2) Hormone sensitive breast cells have hormone receptors which get activated on binding with hormone. Once activated, there is change in expression of specific gene which leads to carcinogenesis. Risk factors for breast cancer are categorized in two groups. 1. Nonmodifiable- old age, height, personal history of benign or other breast disease, positive family history in first degree relatives, genetic mutations in BRCA1 and BRCA2, menstrual history of early menarche and late menopause, exposure to radiation, breast density mammogram and null parity.2. Modifiable risk factors include age at first childbirth, nulliparous women, obesity, less duration of breastfeeding and hormone replacement therapy. (3) Out of these, early age at menarche, late menopause, nulliparous state, and first childbirth at late age and less duration of breast feeding are reproductive risk factors.

Prevalence and profile of risk factors of breast cancer differs region wise. Along with increased prevalence of breast cancer, profile of risk factors is also changing. In our region, Aurangabad is the fastest growing city in Asia with changing lifestyle pattern of women also. At our center, data suggests breast cancer is the most commonly observed malignancy in females. Hence we planned the present study to clarify the association of reproductive risk factors with breast cancer in our patients.

Material and Methods: A total number of 220 histopathologically diagnosed women with carcinoma of breast from March 2009 to November 2013 were included in the present hospital based case control study. Healthy age matched women were included as controls. Controls were the women who were negative on screening by mammography and thorough clinical breast examination in Breast Cancer Awareness camp conducted at our institute. Newly diagnosed patients without past history of major chronic illness were enrolled prior to initiation of treatment from Oncology and Surgery Department of United CIIGMA Hospital. Study was approved by Institutional Ethics Committee and informed consents were obtained from all the subjects on enrollment.

Standard structured pretested valid questionnaire in English and our local language was administered to all participants to record self reported socio demographic data, medical, family, past history, use of hormones and reproductive risk factors. Participants were asked about marital status, number of live births, 
abortions, age at first live birth and breastfeeding duration history. Information was also obtained regarding age at menarche, menopausal status, age at menopause and use of oral contraceptives and hormone replacement therapy.

Data Analysis: After acquisition of complete data, it was compiled and analyzed using SPSS-11. The results were given in the text as number and percentage for qualitative variable like occupation, past disease history, family history of cancer to compare proportion of qualitative/categorical variables in breast cancer cases and controls. Chi-square test/test proportion was applied. Means and standard deviations of quantitative variables in breast cancer cases and control was analyzed by Student's $t$-test and ANOVA. To study the association of risk factors with breast cancer, odds ratio (OR) calculated at 95\% confidence interval (CI). In all statistical analysis, $p<0.05$ were considered significant.

\section{Results: Characteristics of Cases and Controls are Represented in Table 1}

\begin{tabular}{|c|c|c|c|}
\hline Risk factors & $\begin{array}{l}\text { Cases }(n=220) \\
\text { Mean }+/- \text { S.D. }\end{array}$ & $\begin{array}{l}\text { Control }(\mathrm{n}=220) \\
\text { Mean }+/- \text { S.D. }\end{array}$ & P value \\
\hline Age (years) & $54.8+/-18$ & $51.3+/-15$ & NS \\
\hline $\begin{array}{l}\text { History of breast } \\
\text { cancer in first degree } \\
\text { relatives }\end{array}$ & $12(26.4 \%)^{*}$ & $3(6.6 \%)^{*}$ & $<0.05$ \\
\hline $\begin{array}{l}\text { Body Mass Index } \\
\left(\mathrm{Kg} / \mathrm{m}^{2}\right)\end{array}$ & $26.4+/-2.1^{*}$ & $22.2+/-1.8^{*}$ & $<0.05$ \\
\hline $\begin{array}{l}\text { Waist circumference } \\
(\mathrm{cm})\end{array}$ & $92.5+/-3.6^{*}$ & $82.7+/-2.8^{*}$ & $<0.05$ \\
\hline Waist: Hip & $1.4+/-0.33^{*}$ & $0.8+/-0.2$ & $<0.05$ \\
\hline $\begin{array}{l}\text { Age at menarche } \\
\text { (years) }\end{array}$ & $13.3+/-3.2$ & $14.8+/-3$ & NS \\
\hline $\begin{array}{l}\text { Marital status- } \\
\text { Married } \\
\text { Unmarried }\end{array}$ & $\begin{array}{l}212(83 \%) \\
8(17 \%)\end{array}$ & $\begin{array}{l}215(89 \%) \\
5(11 \%)\end{array}$ & NS \\
\hline $\begin{array}{l}\text { Age at first live child } \\
\text { birth (years) }\end{array}$ & $24.3+/-4.5$ & $21.4+/-4.1$ & NS \\
\hline $\begin{array}{l}\text { No. of children } \\
\text { Nulliparous women }\end{array}$ & $\begin{array}{l}3 \\
11(24.2 \%)\end{array}$ & $\begin{array}{l}3 \\
3(6.6 \%)\end{array}$ & $\begin{array}{l}\text { NS } \\
\text { NS }\end{array}$ \\
\hline No. of abortions & $\begin{array}{l}1.72+/-0.6 \\
85(38 \%)\end{array}$ & $\begin{array}{l}1.13+/-0.4 \\
45(20 \%)\end{array}$ & $<0.05$ \\
\hline $\begin{array}{l}\text { Duration of breast } \\
\text { feeding (years) }\end{array}$ & $4.1+/-1.3$ & $5.2+/-1.4$ & NS \\
\hline $\begin{array}{lll}\text { Use of } & \text { Oral } \\
\text { contracetive Pills } & \\
\end{array}$ & $10(22 \%)$ & $3(6.6 \%)$ & NS \\
\hline $\begin{array}{l}\text { Menopausal status } \\
\text { Premenopausal } \\
\text { Postmenopausal } \\
\text { Age at menopause } \\
\text { (years) }\end{array}$ & $\begin{array}{l}64(29 \%) \\
156(71 \%) \\
49.8+/-4.2^{*}\end{array}$ & $\begin{array}{l}70(32.7 \%) \\
150(67.3 \%) \\
42.3+/-3.5^{*}\end{array}$ & $<0.05$ \\
\hline $\begin{array}{l}\text { History of benign } \\
\text { breast disease in past }\end{array}$ & $15(33 \%)^{*}$ & $2(4.4 \%)^{*}$ & $<0.05$ \\
\hline
\end{tabular}

Mean age of the cases was $54.8+/-18$ years ranging from 32 to 76 years and mean age of control was $51.3+/-15$ years ranging from 30 to 78 years. There was no statistical significance difference in cases and control. 12 women (26.4\%) from cases had positive history of breast cancer in first degree relatives. The mean age of 
menarche was $13.3+/-3.2$ years in cases and $14.8+/-3$ years in controls without any statistically significant difference. The mean age at the time of first live birth was $24.3+/-4.5$ years in cases and $21.4+/-4.1$ years in control group. Mean of duration of breast feeding in cases was $4.1+/-1.3$ years and in controls $5.2+/-1.4$ years.

Out of 220 cases 10 women (22\%) were using oral contraceptive pills and 3 women $(6.6 \%)$ from control group. Not a single case and control were reported to be received hormone replacement therapy. None of them was smoker and alcoholic. There was no evidence of occupational exposure to any carcinogen like pesticide. We observed strong positive association of positive family history in first degree relatives (OR- 3.1:95\%CI, 2.12-5.03), number of abortions (OR- 2.8:95\%CI, 1.825.12) and past history of benign breast disease (OR-1.8:95\%CI, 1.-3.03) in cases of breast cancer at our center. Apart from these, anthropometric variables were observed to be positively associated with breast cancer risk. The risk of overweight and obese women to develop breast cancer is 4.2 times higher than lean women (95\%CI: 1.4-6.2). We observed no association between other risk factors.

\section{Discussion}

Role of hormonal and reproductive risk factors has long been well recognized in the development of breast cancer. Various hormones control human female breast, estrogen being the central and important one. Estrogen is required for development of ductal whereas progesterone for lobular component. Hence hormone related risk factors are strong determinant in the etiology of breast cancer.

In our study population, majority (78\%) cases belonged to 4 th to 6 th decade of age with the mean age $54.8+/-18$ years which is similar to that reported in Indian and Asian literature. (4) Early menarche and late menopause are responsible for prolonged duration of exposure to estrogen and progesterone. Risk decreases by $15 \%$ for each year delay in menarche and increases by $3 \%$ each year delay in menopause. (5) Age at menarche it is a predictor of ovulatory frequency in adolescence influencing long lasting risk. Early birth to first live child confers protection against breast cancer because pregnancy transforms breast parenchymal cells into a more stable state, potentially resulting in less proliferation. Women having first child after age of 30 years have twice risk of breast cancer than their counterparts with first live child before 30 . (6) We did not find any statistically significant difference in our both groups ( $p>0.05$ ) with respect to age at menarche, first child birth and duration of breast feeding in our study participants. In our study group, more prevalent modifiable risk factor was obesity, whereas nonmodifiable risk factors were age, family history, past history of benign breast disease and late menopause.

Unmarried and nulliparous women tend to be at higher risk than married women. Recently Bhadoria AS and associates observed strong association of reproductive risk factors with breast cancer in North Indian women. They found early onset of menarche, higher age at marriage, higher mean age at last child birth, lower mean duration of breastfeeding, higher number of abortions, late age at menopause, history of oral contraceptive pills, and a family history of breast cancer among cases compared to the controls. (7)

Butt et al studied reproductive risk factors in Pakistani women and observed association of nulliparity and more age at first live birth with increased breast cancer risk. Breastfeeding was not protective against breast cancer. (8) Navneet Kaur and colleagues reported low prevalence of reproductive risk factors in breast cancer women from Delhi. (9) Lodha R et al found positive family history and use of oral contraceptives as epigenetic strong risk factors in women from urban area. (10)

Not only endogenous but exogenous hormones in the form of consumption of oral contraceptive pills and hormone replacement therapy are at risk of developing breast cancer. In present study, 
none from our cases was receiving hormone replacement therapy while 22\% of the cases were using oral contraceptives for duration of more than 3 months. One study from Iran concluded that ovulatory cycles and hormone replacement therapy was not significant risk factors, but using oral contraceptives recognized as a risk factor. Their results also showed that younger age at first full term pregnancy and number of pregnancies were risk factors for breast cancer in contrast with some other studies. (11)

Obesity is an important and potentially modifiable risk factor for breast cancer because of increasing levels of circulating endogenous estrogen from adipose tissue. In our study participants, postmenopausal women were significantly overweight $(\mathrm{p}<0.05)$ with mean BMI 26.4 +/- 2.5 $\mathrm{Kg} / \mathrm{m}^{2}$. Body size has opposite influences as a risk factor on breast cancer in premenopausal and postmenopausal women. Higher body weight is associated with lower risk in premenopausal women whereas risk increases with BMI in postmenopausal women. This suggests the importance of maintenance of weight by modifying lifestyle through healthy dietary habits and increasing physical activities. (12) Also protective effect of long duration of breastfeeding was found to be protective in among premenopausal women, not in postmenopausal women in one of multicenter study from India. (13)

Epidemiologically, breast cancer holds unique position to represent an enormous public health issue due to changing prevalence of established risk factors. Although etiology of breast cancer is complex and multifactorial involving genetic, hormonal and environmental factors, various studies showed significant role of reproductive risk factors in breast tumor genesis. (14) Estradiol, potent endogenous estrogen secreted from ovary is important source of estrogen for regulation of differentiation and proliferation of breast epithelial cells. Several studies suggested positive association of testosterone, sex hormone binding globulins with breast cancer. This suggests central role of endocrinological risk factors especially endogenous estrogen in initiation, progression and promotion of breast cancer.

\section{Conclusion}

Present study has provided possible association of hormone related risk factors like postmenopausal status, age, late menopause with raised BMI with breast cancer in Indian women. Epidemiological studies for identification of risk factors of breast cancer in multiple subpopulations are desperately warranted in Indian context.

\section{References}

1. Chopra, R. (2001). "The Indian Scene," Journal of Clinical Oncology, 1918 Suppl: 106S-111S

2. Programme, N. C. R. (2009). "Time Trends in Cancer Incidence Rates 1982-2005," Bangalore, India: Indian Council of Medical Research.

3. Dhillon, P. K. "South Asia Network for Chronic Disease," Public Health Foundation of India Breast Cancer Factsheet.

4. Mohapatra, M. \& Satyanarayana, S. (2013). "Evaluation of Clinico: Pathologic Findings of Breast Carcinoma in a General Hospital in Southern India," Indian Journal of Cancer 50(4) 297-301.

5. World Cancer Report (2008) 'International Agency for Research on Cancer,' Lyon.

6. Evans, D. G. R. \& Howell, A. (2007). "Breast Cancer Risk-assessment Models," Breast Cancer Research, 9:213

7. Bhadoria, A. S., Kapil, U., Sareen, N. \& Singh, P. (2013). "Reproductive Factors and Breast Cancer: A Case-Control Study in Tertiary Care Hospital of North India," Indian Journal of Cancer 50(4) 316-21. 
8. Butt, Z., Shahbaz, U., Naseem, T., Ashfaq, U., Khan, U. A., Khan, M. R., Hashmim, A. T. \& Bukhari M. H. (2009). 'Reproductive Risk Factors for Female Breast Cancer: A Case - Control Study,' Annals Vol 15. No.4 206-10.

9. Kaur, N., Attam, A., Saha, S. \& Bhargava, S. K. (2011). "Breast Cancer Risk Factor Profile in Indian Women," JIMSA Vol. 24(4)163-5.

10. Lodha, R., Joshi, A., Paul, D., Lodha, K. M., Nahar, N., Shrivastava, A., Bhagat, V. K. \& Nandeshwar, S. (2011). "Association between Reproductive Factors and Breast Cancer in an Urban Set up at Central India: A Case-Control Study," Indian Journal of Cancer; 48(3) 303-7.

11. Rezaeisadrabadi, M., Zahir, S. T., Mortazavizadeh, M., Emamimeybodi, T., Absalan, A. \& Daneshbodi, H. (2011). "Study on the Relationship between Breast Cancer and Female Endocrine Conditions, Hormone Therapy and Oral Contraceptive Usage among Women in Yazd, Iran during 2006-2007," MiddleEast Journal of Scientific Research 8 (1): 34-39.
12. Murtaugh, M. A., Sweeney, C., Giuliano, A. R., Herrick, J. S., Hines, L., Byers, T. et al. (2008). "Diet Patterns and Breast Cancer Risk in Hispanic and NonHispanic White Women: The FourCorners Breast Cancer Study," American Society for Clinical Nutrition; 87:978-84.

13. Gajalakshmi, V., Mathew, A., Brennan, P., Rajan, B., Kanimozhi, V. C., Mathews, A., Mathew, B. S. \& Boffetta, P. (2009). "Breastfeeding and Breast Cancer Risk in India: A Multicenter Case-Control Study," International Journal of Cancer: 125, 662-665.

14. Pakseresht, S., Ingle, G. K., Bahadur, A. K., Ramteke, V. K., Singh, M. M., Garg, S. \& Agarwal, P. N. (2009). "Risk Factors with Breast Cancer among Women in Delhi," Indian Journal of Cancer; 46:132-8. 